\title{
ASYMPTOTICS FOR NONLOCAL EVOLUTION PROBLEMS BY SCALING ARGUMENTS
}

\author{
TATIANA I. IGNAT
}

Abstract. In this paper we consider a nonlocal evolution problem and obtain by a scaling method the first term in the asymptotic behavior of the solutions. The method employed treats in different way the smooth and the rough part of the solution.

Mathematics subject classification (2010): 35B40, 45A05.

Keywords and phrases: nonlocal diffusion, large time behavior.

\section{REFERENCES}

[1] F. Andreu, J.M. Mazón, J.D. Rossi And J.J. Toledo-Melero, Nonlocal diffusion problems. Mathematical Surveys and Monographs 165. Providence, RI: American Mathematical Society (AMS); Madrid: Real Sociedad Matemática Española. xv, 256 p., 2010.

[2] P.W. BATES, P.C. FIFE, X. REN AND X. WANG, Traveling waves in a convolution model for phase transitions, Arch. Rational Mech. Anal., 138, 2 (1997), 105-136.

[3] C. CarRillo and P. Fife, Spatial effects in discrete generation population models, J. Math. Biol., 50, 2 (2005), 161-188.

[4] E. Chasseigne, M. Chaves And J. D. Rossi, Asymptotic behavior for nonlocal diffusion equations, J. Math. Pures Appl. (9), 86, 3 (2006), 271-291.

[5] Q. Du, J.R. KAMm, R.B. LehoucQ AND M.L. PARKs, A new approach for a nonlocal, nonlinear conservation law, SIAM J. Appl. Math., 72, 1 (2012), 464-487.

[6] M. Escobedo ANd E. ZuAZUA, Large time behavior for convection-diffusion equations in $\mathbb{R}^{N}$, J. Funct. Anal., 100, 1 (1991), 119-161.

[7] M. Escobedo, J.L. VÁzQuez And E. ZuAZuA, Asymptotic behaviour and source-type solutions for a diffusion-convection equation, Arch. Rational Mech. Anal., 124, 1 (1993), 43-65.

[8] P. FIFE, Some nonclassical trends in parabolic and parabolic-like evolutions, In Trends in nonlinear analysis, pages 153-191. Springer, Berlin, 2003.

[9] P.C. FIFE AND X. WANG, A convolution model for interfacial motion: the generation and propagation of internal layers in higher space dimensions, Adv. Differential Equations, 3, 1 (1998), 85-110.

[10] M.H. Giga, Y. Giga And J. SAal, Nonlinear partial differential equations, Progress in Nonlinear Differential Equations and their Applications, 79. Birkhäuser Boston Inc., Boston, MA, 2010. Asymptotic behavior of solutions and self-similar solutions.

[11] L.I. IGNAT AND J.D. Rossi, A nonlocal convection-diffusion equation, J. Funct. Anal., 251, 2 (2007), $399-437$.

[12] L.I. IGNAT AND J.D. Rossi, Refined asymptotic expansions for nonlocal diffusion equations, J. Evol. Equ., 8, 4 (2008), 617-629.

[13] L.I. IGNAT AND J.D. Rossi, Decay estimates for nonlocal problems via energy methods, J. Math. Pures Appl. (9), 92, 2 (2009), 163-187.

[14] G. KARCH AND K. SUZUKI, Spikes and diffusion waves in a one-dimensional model of chemotaxis, Nonlinearity, 23, 12 (2010), 3119-3137.

[15] P. LAURENÇOT, Asymptotic self-similarity for a simplified model for radiating gases, Asymptot. Anal., 42, 3-4 (2005), 251-262. 
[16] D. SERRE, $L^{1}$-stability of nonlinear waves in scalar conservation laws, In Evolutionary equations. Vol. I, Handb. Differ. Equ., pages 473-553. North-Holland, Amsterdam, 2004.

[17] J. Simon, Compact sets in the space $L^{p}(0, T ; B)$, Ann. Mat. Pura Appl. (4), 146 (1987), 65-96. 